\title{
An essay on ecosystem availability of Nicotiana glauca graham alkaloids: the honeybees case study
}

Konstantinos M. Kasiotis ${ }^{1 *}$ (D) Epameinondas Evergetis ${ }^{2 *}$, Dimitrios Papachristos ${ }^{3}$, Olympia Vangelatou ${ }^{2}$, Spyridon Antonatos ${ }^{3}$, Panagiotis Milonas ${ }^{4}$, Serkos A. Haroutounian² and Kyriaki Machera ${ }^{1}$

\begin{abstract}
Background: Invasive plant species pose a significant threat for fragile isolated ecosystems, occupying space, and consuming scarce local resources. Recently though, an additional adverse effect was recognized in the form of its secondary metabolites entering the food chain. The present study is elaborating on this subject with a specific focus on the Nicotiana glauca Graham (Solanaceae) alkaloids and their occurrence and food chain penetrability in Mediterranean ecosystems. For this purpose, a targeted liquid chromatography electrospray tandem mass spectrometric (LCESI-MS/MS) analytical method, encompassing six alkaloids and one coumarin derivative, utilizing hydrophilic interaction chromatography (HILIC) was developed and validated.
\end{abstract}

Results: The method exhibited satisfactory recoveries, for all analytes, ranging from 75 to $93 \%$, and acceptable repeatability and reproducibility. Four compounds (anabasine, anatabine, nornicotine, and scopoletin) were identified and quantified in $3 \mathrm{~N}$. glauca flowers extracts, establishing them as potential sources of alien bio-molecules. The most abundant constituent was anabasine, determined at $3900 \mathrm{\mu g} / \mathrm{g}$ in the methanolic extract. These extracts were utilized as feeding treatments on Apis mellifera honeybees, resulting in mild toxicity documented by $16-18 \%$ mortality. A slightly increased effect was elicited by the methanolic extract containing anabasine at $20 \mu \mathrm{g} / \mathrm{mL}$, where mortality approached $25 \%$. Dead bees were screened for residues of the $\mathrm{N}$. glauca flower extracts compounds and a significant mean concentration of anabasine was evidenced in both 10 and $20 \mu \mathrm{g} / \mathrm{mL}$ treatments, ranging from 51 to $92 \mathrm{ng} / \mathrm{g}$ per bee body weight. Scopoletin was also detected in trace amounts.

Conclusions: The mild toxicity of the extracts in conjunction with the alkaloid and coumarin residual detection in bees, suggest that these alien bio-molecules are transferred within the food chain, suggesting a chemical invasion phenomenon, never reported before.

Keywords: Nicotiana glauca, Anabasine, Nicotine, Invasive plants, Honeybees, HILIC

*Correspondence: K.Kasiotis@bpi.gr; epaev@mac.com

${ }^{1}$ Laboratory of Pesticides'Toxicology, Department of Pesticides Control and Phytopharmacy, Benaki Phytopathological Institute, 8 St. Delta str., 14561 Kifissia, Attica, Greece

${ }^{2}$ Laboratory of Nutritional Physiology and Feeding, Agricultural University of Athens, lera Odos 75, 11855 Athens, Greece

Full list of author information is available at the end of the article

\begin{abstract}
Introduction
Invasive Alien Species (IAS) is a terminology recently established for the description of taxa presenting an aggressive expansion. According to the Convention on Biological Diversity, IAS refer to thriving populations of non-native taxa, which apply severe pressures on ecosystems and local biodiversity through competition, predation, and transmission of pathogens. In specific, IAS has been found to drive globally significant socio-economic,
\end{abstract}

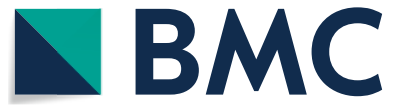

(C) The Author(s) 2020. This article is licensed under a Creative Commons Attribution 4.0 International License, which permits use, sharing, adaptation, distribution and reproduction in any medium or format, as long as you give appropriate credit to the original author(s) and the source, provide a link to the Creative Commons licence, and indicate if changes were made. The images or other third party material in this article are included in the article's Creative Commons licence, unless indicated otherwise in a credit line to the material. If material is not included in the article's Creative Commons licence and your intended use is not permitted by statutory regulation or exceeds the permitted use, you will need to obtain permission directly from the copyright holder. To view a copy of this licence, visit http://creativeco mmons.org/licenses/by/4.0/. The Creative Commons Public Domain Dedication waiver (http://creativecommons.org/publicdomain/ zero/1.0/) applies to the data made available in this article, unless otherwise stated in a credit line to the data. 
health, and ecological costs that consequent to critical risks for agriculture, forestry, and fisheries $[1,2]$. Besides, IAS impacts aggravated by climate change, pollution, and human intervention in natural ecosystems emerge as the second most severe threat, after habitat loss, for ecosystems and biodiversity conservation [3].

In Europe alone, herbal IAS account to 5.789 taxa [4], applying pressures that have been identified as competition events, pathogens introduction and transmission [5], and pollinators decline [6, 7]. This last pressure may be explained by the consideration of herbal IAS as a significant feed resource, providing pollinators with both nectar and pollen [8-10]. The consumption of IAS nectar is a problem because of its secondary metabolites content, which has been found to present toxic effects to pollinators [11]. In the same context, and in relation to food commodities, compounds such as alkaloids are controlled under the maximum residue limits (MRLs) Regulation 396/2005 and its respective amendments [12]. MRLs are established for some of them, but not in apiculture matrices. Hence, in cases of positives' detection, the general default MRL of $0.01 \mathrm{mg} / \mathrm{kg}$ can be applied.

Tiedeken et al. [7] elaborating further on this subject concluded that feeding on IAS might drive the exposure of native pollinators to various levels of toxic phytochemicals. Among nectar's secondary metabolites, alkaloids consist a clear and identifiable target for the attribution of nectar toxicity [13]. Alkaloids are generally acknowledged as the cutting edge of plants defence mechanisms deterring herbivores from damaging plant tissues [14]. Mollo et al. [15], in their effort to describe the phenomenon of natural products introduction by IAS in marine ecosystems proposed the term Alien Bio-Molecules [15], in order to distinguish them by other xenobiotics of human origin, pioneering thus the study of invasive phytochemicals ecological implications.

The present study is aiming to ameliorate these previous research results on the adverse effects of invasive molecules, through the investigation of their ecosystem availability. Consequently, Nicotiana glauca Graham (N. glauca, Solanaceae), whose nectar contains nicotine like alkaloids, was selected as a focal point. N. glauca is a fast-growing shrub or small tree native to South America that has been introduced in North America, Europe, and Asia, consisting thus an IAS of global expansion [16]. Although hummingbirds pollinate $N$. glauca in its native range [17], bees and other insects have been observed to visit its flowers and impale the base of the corolla to access its nectar (Fig. 1).

While the study of $N$. glauca flowers alkaloid content is aiming to delineate the availability of invasive molecules to indigenous pollinators communities, the use of honeybees (Apis melifera) fed by flowers extracts, standardised

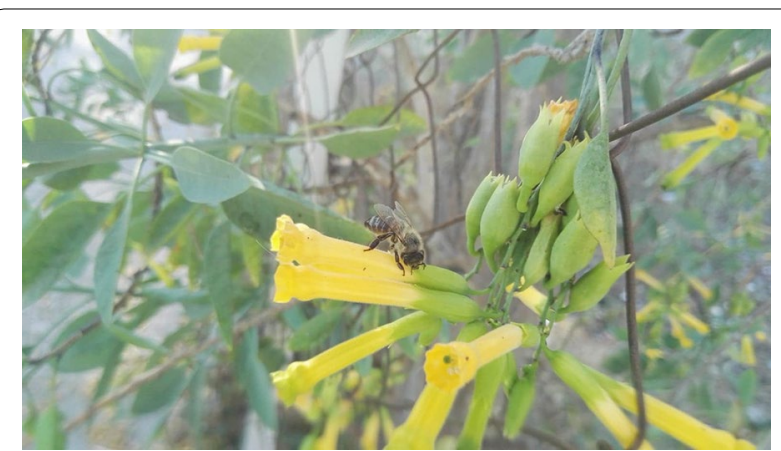

Fig. 1 A honeybee foraging a Nicotiana glauca flower (photo taken by our group in Greece)

on the prevailing alkaloid concentration, aspires to investigate any potential adverse effect on bees survival after exposure. To elucidate this plant-insect interaction framework, an analytical method was developed, validated and applied to investigate alkaloids levels in plant extracts and honeybees, devoting specific focus on the $N$. glauca alkaloid content and its fate upon consumption by honeybees.

To our knowledge, the presented herein results comprise the first in depth exploration of the $N$. glauca reproductive organs in respect with their alkaloid content, even though the study of $N$. glauca alkaloid content goes back almost 75 years [18] and quite early managed to define anabasine as the prevailing pyridine alkaloid [19]. The Baldwin and Ohnmeiss [20] study provided a significant conclusion, indicating that foraging may induce alkaloid content of $N$. glauca [20], a result soon confirmed by other researchers [21]. In 2004, TadmorMelamed et al. presented the alkaloid content of $N$. glauca nectar and discussed on the ecological implications regarding plant's pollinators. Kaczorowski et al. [22] indicated that foraging impacts on $N$. glauca are not restricted to morphological aspects but also may regulate the alkaloid content of nectar, promoting the biosynthesis of anabasine against nicotine. Another element of alkaloid content and foraging interaction was reported soon after by Aizenberg-Gershtein et al. [23], which correlated the foragers' preferences with the differentiated floral microbiome as a result of alterations in alkaloid content. The final conclusion of Kaczorowski and Markman [24] that plant secondary metabolites ingestion may lead to reduced foraging performance, which in turn could significantly affect an organism's foraging efficiency, drove our consequent experimentation aiming to delineate the alkaloids fate and impacts on honeybees that forage on $N$. glauca flowers.

Last but not least, from the alkaloids reported in $N$. glauca, and to the best of our knowledge, only for 
nicotine an acute contact $\mathrm{LD}_{50}>500 \mu \mathrm{g} / \mathrm{g}$ bee body weight (bw), is established, which classifies nicotine as a moderate toxicant for bees [25]. Therefore, any additional data that associate alkaloids consumption to honeybees effects is of high significance, and to an extent is provided in the herein presented work.

\section{Materials and methods Materials}

Herbal material consisted of Nicotiana glauca Graham flowers -including calyx-, which were collected from Paros island, Greece $\left(37^{\circ} 07^{\prime} 01^{\prime \prime} \mathrm{N}, 25^{\circ} 14^{\prime} 08^{\prime \prime} \mathrm{E}\right)$, on August 9, 2015. Herbal material was dried naturally and weighted to $67 \mathrm{~g}$. The dried herbal material was finely grinded and subjected to successive extraction with n-hexane, dichloromethane, and methanol. In specific each extract was obtained by the application of $1.5 \mathrm{~L}$ of solvent divided into three repetitions $(0.5 \mathrm{~L}$ each) of three days duration each. The extracts were condensed through vacuum and heat-assisted evaporation (Büchi Rotavapor R-210 equipped with Büchi vacuum pump V-700, Vacuum controller V-850, and Julabo F12 cooling unit), and subsequently subjected to freeze-drying (Scientz-18 N, Freeze dryer). The yield of each solvent's extract (in g per $100 \mathrm{~g}$ of dried flowers) were as follows: (a) hexane, 4.2 (b) dichloromethane, 1.8, and (c) $\mathrm{MeOH}, 12.2$.

A beehive of Apis mellifera ssp. cecropia, a taxon originating in southern Greece, was used as pollinator for the study. The apiary consisted from 25 standard Langstroth hives with one hive-body containing 10 frames. The hives were not subjected in chemicals treatment for the control of pests and diseases. The bees were recruited from two brood frames of a single hive; young worker bees (3-13 days old "nurse bees") were captured from the hive, put into a plastic box and transferred to the laboratory. In addition, dead bees were obtained from the reservoir of routine honeybee samples that Benaki Phytopathological Institute receives for pesticide residue analysis and assessment of Varroa and Nosema infestation and were utilized as control samples. These samples were devoid of pesticide residues and the herein targeted compounds.

The following chemical standards and reagents were used in the course of our study: (-)-cotinine, (R,S)-anatabine, and myosmine purchased from Santa Cruz Biotechnology, Inc., $( \pm)$-anabasine and scopoletin from Acros Organics, $( \pm)$-nicotine from Cayman Chemicals, and nornicotine from Sigma Aldrich (purity for all standards was above 90\%). Acetonitrile LC-MS grade and extra pure LC-MS water was obtained from Merck (Darmstadt, Germany), magnesium sulphate $\left(\mathrm{MgSO}_{4}\right)$ was purchased from Scharlab S.L. (Barcelona, Spain), sodium acetate from Panreac (Barcelona, Spain), primary secondary amine (PSA) from Interchim (Montluçon
France), and octyldecylsilane (C18) endcapped from Macherey Nagel (Düren, Germany). Dichloromethane and hexane (pro analysis) were obtained from Fisher Scientific (Pittsburgh, USA).

\section{Methods \\ Bioassay}

Bees feeding bioassay was conducted in groups of $40-50$ individuals, using three replicates per treatment (see treatments below). The groups of $40-50$ bees were placed in wire-screened plastic holding-cages $(30 \times 30 \times 30 \mathrm{~cm})$ and provided with $50 \%(\mathrm{w} / \mathrm{v})$ sucrose solution and water for $24 \mathrm{~h}$ in order to acclimatize to laboratory conditions. Bees were deprived of food for $5 \mathrm{~h}$, before the administration of $N$. glauca extracts. Then, the appropriate solutions (solutions are presented below) of $N$. glauca extracts were prepared on with sucrose and water, poured into small plates $(10 \mathrm{~cm}$ in diameter), and provided to bees. One plate containing $20 \mathrm{~mL}$ of the appropriate solution of $N$. glauca extracts was placed into each cage except the control were bees fed with $20 \mathrm{~mL} 50 \%$ (w/v) sucrose solution. Treated food remained in the cages for $24 \mathrm{~h}$. Then, all treated plates were replaced by new plates that contained only sucrose solutions. For each treatment, three replicates of $40-50$ bees were used.

\section{Feeding solutions}

After determining the composition of each dry extract, three stock solutions were prepared through the addition of a $50 \%(\mathrm{w} / \mathrm{v})$ sucrose solution (in water) in each dry extract (devoid of organic solvent residues) benefiting from the high-water solubility of anabasine [26] and anatabine [27], and the moderate solubility of nornicotine [28], and scopoletin [29]. Then, by appropriate dilution with the addition of $50 \%(\mathrm{w} / \mathrm{v})$ sucrose solution in for each feeding solution to present a constant concentration of $10 \mu \mathrm{g} / \mathrm{mL}$ of anabasine. The rationale behind the selection of this concentration stems from a pertinent study on the feeding of foraging honeybees to secondary molecules that mimic floral nectar [30]. In this study, bees were dissuaded by such concentration of anabasine.

In addition to these three feeding solutions (see Additional file 1: Table S1 for components' concentration in the extracts), another methanolic solution standardised to $20 \mu \mathrm{g} / \mathrm{mL}$ of anabasine (methanol extract $20 \mu \mathrm{g} / \mathrm{mL}$ ) was prepared also accompanied by the control feeding solution containing only sucrose $(50 \%, w / v)$. The feeding solutions were administered in a constant dose of $20 \mathrm{~mL}$ per cage, which remained in the cages for $24 \mathrm{~h}$ and then were replaced by $50 \%(\mathrm{w} / \mathrm{v})$ sucrose solutions. Honeybees' mortality was assessed in 0,4 and 8 days post-treatment. 
Liquid chromatography-tandem mass spectrometry An Agilent Technologies 6410 Triple Quad LC/MS system was used, equipped with a Nitrogen Generator (NitroFlowLab). Optimum LC separation condition, using HILIC conditions described in the literature [31] were embraced with the flow rate modified to $0.4 \mathrm{~mL} /$ min, working under isocratic conditions. Thus, the mobile phase was composed of a mixture of acetonitrile and water $(85: 15, \mathrm{v} / \mathrm{v})$ containing $5 \mathrm{mmol} / \mathrm{L}$ ammonium acetate ( $\mathrm{pH} 5)$. The sample injection volume was $10 \mu \mathrm{L}$. Separation occurred on a HILIC column (Agilent, Zorbax HILIC Plus, Narrow Bore RR, $2.1 \times 100$ mm, $3.5 \mu \mathrm{m}$ ).

Reversed phase (RP) separation was achieved after injecting $10 \mu \mathrm{L}$ of sample on a RP column (ZORBAX Eclipse XDB-C18 Agilent, $2.1 \times 150 \mathrm{~mm}, 3.5 \mu \mathrm{m})$ using a gradient system consisting of (A) Water with $5 \mathrm{mM}$ ammonium formate, $0.1 \%$ formic acid, and (B) Methanol with $5 \mathrm{mM}$ ammonium formate, $0.1 \%$ formic acid. The flow rate was set at $0.3 \mathrm{~mL} \mathrm{~min}{ }^{-1}$ and the column gradient program consisted of: linear ramping from 0 to $100 \%$ B within 10, 10-15 min 100\% B. Then gradient system returned from $15-20 \mathrm{~min}$, to initial conditions (100\% A), where it stayed for additional $5 \mathrm{~min}$ to equilibrate. The mass spectrometer was operated in Multiple Reaction Monitoring (MRM) mode with positive Electron Spray Ionization, and both quadrupoles were set at unit mass resolution. Nitrogen was used as nebulizer and collision gas. The software used for instrument control was Agilent Mass Hunter data acquisition Triple Quad B.01.04 software and for data processing Agilent MassHunter Workstation Qualitative Analysis B.01.04 software.

\section{Solutions and sample preparation}

Stock solutions of each analytical standard were prepared at $1000 \mu \mathrm{g} / \mathrm{mL}$ in methanol. Subsequently, an intermediate stock solution was prepared at $10 \mu \mathrm{g} / \mathrm{mL}$ containing all analytes. The latter was used to prepare the working solutions used for calibration purposes. This approach was incorporated for the spiking of both plant and honeybees' extracts. All working solutions were prepared on a daily basis, while stock solutions were kept stored at $-18^{\circ} \mathrm{C}$.

Concerning the 3 dry herbal extracts, they were dissolved in methanol to provide the respective stock solutions. Consequently, each stock solution was diluted with methanol to afford an extract concentration of $100 \mathrm{ppm}$ that was filtered (PTFE, 45) and then subjected to LCESI-MS/MS analysis.

The honeybees' sample preparation was based on a modified "quick, easy, cheap, effective, rugged, and safe" (QuEChERS) protocol [32]. More specifically, $1 \mathrm{~g}$ of honeybees (approximately 10-15 dead individuals) was mixed with water $(2 \mathrm{~mL})$ using a glass rod, and acetonitrile was added $(7 \mathrm{~mL})$. The mixture was homogenized for $4 \mathrm{~min}$ (Ultra Turax homogenizer, 20,000 rpm) and then transferred to a falcon tube containing $\mathrm{MgSO}_{4}(1 \mathrm{~g})$, and sodium acetate $(0.2 \mathrm{~g})$. The resulting mixture was shaken for $1 \mathrm{~min}$, and vortex-mixed for $1 \mathrm{~min}$. After centrifugation at $4000 \mathrm{rpm}$ and $10^{\circ} \mathrm{C}$ for $5 \mathrm{~min}$, the upper organic phase was transferred to a separate falcon tube containing $\mathrm{MgSO}_{4}$ (500 mg), PSA (50 mg), and C18 endcapped $(25 \mathrm{mg})$. After shaking, and vortex-mixing for total $2 \mathrm{~min}$, the supernatant solution was decanted and evaporated to dryness using a nitrogen stream. The dry extract was reconstituted with acetonitrile $(1 \mathrm{~mL})$, filtered, and injected to the LC-ESI-MS/MS system.

\section{Validation methodology}

The proposed method's validation was structured upon the guidelines set by the International Conference on Harmonization [33], elaborated by later approach, pertinent to chemical measurements in natural products research [34]. As validation parameters were set:

\section{Precision (intra-day, inter-day)}

The precision of the chromatographic method was expressed as the relative standard deviation, RSD \% of the repeatability (intra-day) and intermediate precision (inter-day) analyses $(\mathrm{n}=3)$ over the three days studied, after injection of quality control samples, fortified at $200 \mathrm{ng} / \mathrm{g}$ with appropriate volume of the analytes mix solution. Intra-day, and inter-day precision were considered acceptable when RSD\% were $<20 \%$.

\section{Accuracy-trueness (recovery)}

Standard addition was used for the recovery study concerning the $N$. glauca flower extracts, and conducted at three concentration levels (50, 200, and $1000 \mathrm{ng} / \mathrm{g}$ ). $N$. glauca plant extracts spiked with the analytes mix solution at the same concentration levels on the same day or within three different days were extracted to determine repeatability $(n=3)$ and reproducibility $(n=3)$, respectively.

\section{Linearity}

Linearity was acceptable when regression coefficient was higher than 0.99 , and residuals were less than $20 \%$.

\section{Detection and quantitation limit ( $L O D$ and $L O Q$ respectively)}

LOD and LOQs determinations were based on the standard deviation of the response and the slope, following Eqs. 1 and 2. In regard with the honeybees' analytical method validation, the only differentiation was the LOQ definition that was defined as the lowest fortification level with acceptable precision and accuracy. 


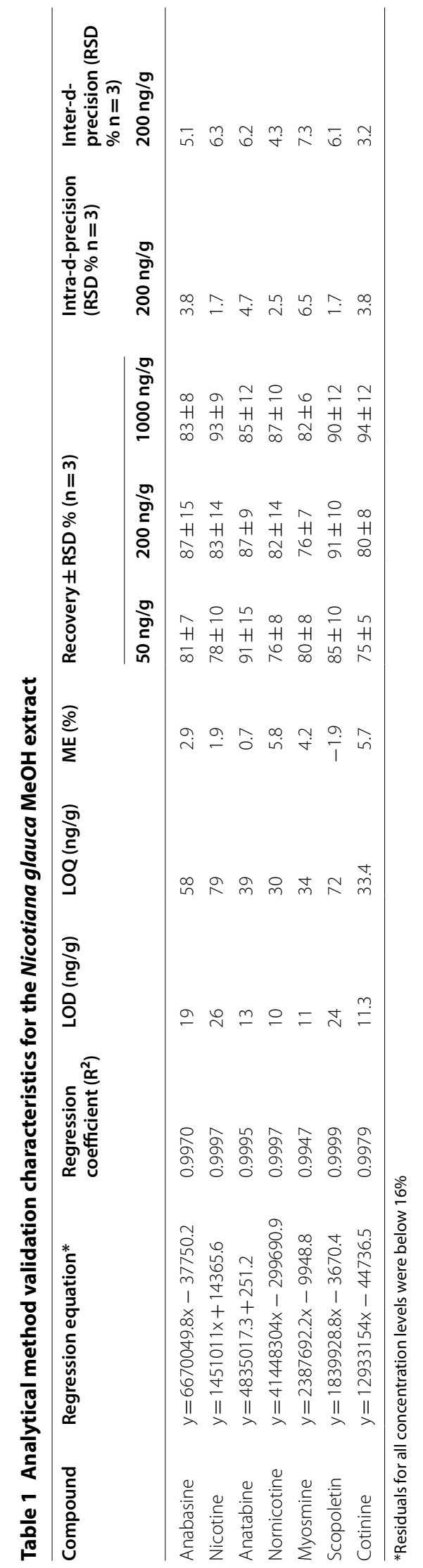




$$
L O D=\frac{3.3 \sigma}{S}
$$

Equation 1: Limit of Detection calculation algorithm

$$
L O Q=\frac{10 \sigma}{S}
$$

Equation 2: Limit of Quantification calculation algorithm.

$\sigma=$ standard deviation of the response,

$\mathrm{S}=$ slope of the calibration curve.

The calibration curves (in solvent and matrix extract) were determined using the dilute standard solution of the mixture of analytes investigated in the proposed analytical method. Calibration curves varied from 10 to $1000 \mathrm{ng} / \mathrm{mL}$, containing seven calibration points $(10$, $50,100,200,300,500,1000)$. To estimate if the matrix, affects the peak area of the analytes of the method significantly, therefore sensitivity, the slopes of the calibration lines obtained for plant and honeybees extract after standard addition $\left(\mathrm{b}_{\text {matrix }}\right)$, and the solvent $\left(\mathrm{b}_{\text {solvent }}\right)$ were divided to determine the matrix factor and the \% matrix effect (ME) was calculated as indicated in Eq. 3.

$$
\% \mathrm{ME}=\left(1-\frac{\mathrm{b}_{\text {matrix }}}{\mathrm{b}_{\text {solvent }}}\right) \times 100
$$

Equation 3: Matrix effect calculation algorithm.

\section{Statistical analyses}

To analyze the differences of $N$. glauca extracts on the bee mortality among the different observation days, repeated measures ANOVA (RM-ANOVA) were performed. The percentage mortalities were transformed to arcsine square-root values prior to analysis in order to satisfy assumptions of the parametric analysis. When RM-ANOVA indicated a significant difference among treatments, Bonferroni test was used to identify the differences between treatments and control. Analyses were performed using the statistical package SPSS 22.0 (SPSS Inc., Chicago, IL, U.S.A.).

\section{Results}

\section{Analytical method validation}

For the analytical methods validation, the dried organic extracts were fortified with known amount of the mix solution of the alkaloids and scopoletin. The outcomes of validation study, presented for the methanolic extract in Table 1, showed that all analytical figures of merit were acceptable. Recoveries, for all analytes, for the three studied concentration levels varied from 75 to $93 \%$, with satisfactory RSD\% values $(\leq 15 \%)$. Similar values, (Additional file 1: Tables S2, S3), were obtained for the other two extracts and in the same magnitude. Repeatability (intra-day precision) and inter-day precision were acceptable as demonstrated by the RSD\% values that were below $10.5 \%$. More specifically, recoveries for all compounds varied from 74 to $100 \%$, in the three concentration levels studied, with $\mathrm{RSD} \%$ values $<11 \%$. LODs for the plant extracts were calculated as described above and varied from 10 to $26 \mathrm{ng} / \mathrm{g}$ extract, while LOQs fluctuated from 30 to $79 \mathrm{ng} / \mathrm{g}$ extract. Concerning honeybees an LOQ (for all analytes) was established at $40 \mathrm{ng} / \mathrm{g}$ bee bw. The latter was fit for the purpose of the study and was supported by acceptable precision and accuracy, as indicated in Additional file 1: Table S4.

One often unanticipated etiology of low quality analytical results is the matrix interference. Even though the MS/MS technique is considered less susceptible than other analytical techniques and detectors (such as simple MS, or UV detector), still matrix effect is vastly reported. In this context, the assessment of matrix effects demonstrated a slight enhancement of the signal of the analytes, except for scopoletin (slight suppression), overall being characterized as not significant. Non-significant was also the ME for all analytes using the QuEChERS extraction of chemicals from bees (see ME values in Additional file 1: Table S2, and a respective blank chromatogram, Additional file 1: Figure S1). Separation of analytes under RP chromatography conditions was not successful especially for anatabine and nicotine. In particular, the resolution of their isomers could not be evidenced under such conditions (Additional file 1: Figure S2). Even though the MS/MS environment does not require substantial resolution among analytes in multianalytes methods, it was decided to enhance the separation of the compounds and their isomers, optimizing the peak shape. The latter was accomplished by utilizing hydrophilic interaction chromatography conditions [35].

\section{Herbal extracts}

The qualitative analyses of the three $N$. glauca extracts included as target molecules the alkaloids anabasine, anatabine, nicotine, nornicotine, cotinine, myosmine, and the coumarin scopoletin (for MRM transitions and retention times see Additional file 1: Figure S3A-G). The results presented in Table 2, indicated as more diverse the methanolic extract, which contained anabasine, anatabine, nornicotine and scopoletin, while dichloromethane extract proved to contain only anabasine and anatabine, and hexane extract only anabasine. The quantitative analysis that was performed in the three $N$. glauca extracts delineated the concentrations of anabasine, anatabine, scopoletin and nornicotine. The methanolic extract exhibited the highest concentrations of all constituents, with prevailing compound anabasine (for respective chromatogram see Additional file 1: Figure 


$$
\text { E }
$$


S4), and lower levels of anatabine, scopoletin, and nornicotine. Dichloromethane and hexane extracts presented a much lower and descending concentration of anabasine, respectively. Nornicotine is a demethylation product of nicotine that is reported to occur in Nicotiana species [36], and was evidenced in the methanolic extract. Similarly, scopoletin, which has been reported as an active constituent of $N$. glauca [37] was quantified as well. On the other hand, nicotine, myosmine, and cotinine were not detected in any of the extracts.

\section{Feeding bioassay}

The feeding experiment provided two significant sets of results. The first regards the observed bees' mortality rates, which is presented in Fig. 2; the second set consists of the records of alkaloids quantities recorded in the dead bees of the feeding bioassay, which are presented in Table 3. Control honeybees' mortality until the 4th day did not exceed the threshold of $10 \%$ set by the Organization for Economic Co-operation and Development (OECD) in the guidelines for honeybees' acute oral toxicity test [38].

All N. glauca extracts had a significant effect on bees' mortality compared to control (Bonferroni test: $\mathrm{p}<0.05$ ), presenting similar mortality rates between 16 and $18 \%$, with the exception of methanol extract's feeding solution containing anabasine at $20 \mu \mathrm{g} / \mathrm{mL}$, which presented an augmented mortality rate by $23 \%$ in the 4 th day. Both feeding treatment and post treatment period had a significant effect on bees mortality $\mathrm{F}=21.08 ; \mathrm{df}=4,10$; $\mathrm{p}<0.001) ; \mathrm{F}=104.08 ; \mathrm{df}=8,20 ; \mathrm{p}<0.001)$. No significant interaction between the two factors was found $(\mathrm{F}=0.27$; $\mathrm{df}=8,20 ; \mathrm{p}=0.97)$.

\section{Residues in bees}

Dead bees were analyzed for the presence of the four constituents detected in the respective extracts (see Table 3 for results). Anabasine was detected in dead bees from all the feeding solutions, confirming its uptake from the plant extracts. In specific, anabasine was found on an average concentration of $9.2 \mathrm{ng}$ per bee (equivalent to $\left.92 \mathrm{ng} / \mathrm{g}_{\text {bee bw }}\right), 5.1 \mathrm{ng}$ per bee, $4.7 \mathrm{ng}$ per bee, and $4.3 \mathrm{ng}$ per bee in methanol extract $20 \mu \mathrm{g} / \mathrm{mL}$, methanol, dichloromethane and hexane extract $10 \mu \mathrm{g} / \mathrm{mL}$ respectively (an indicative chromatogram is presented in Additional file 1: Figure S5). Scopoletin traces were detected in dead bees from feeding solutions containing it. These residual invasive molecules quantities originated exclusively from the feeding solutions content.

\section{Estimates on bees daily anabasine exposure}

To facilitate subsequent discussion, each $N$. glauca flower produces in Greece an average of $23.5 \mu \mathrm{L}$ of nectar with sucrose mean concentration of $25.2 \%$ [17]. Taking into account that the minimum daily need of an adult bee for sucrose is $4000 \mu \mathrm{g}[39,40]$ it is estimated that each bee will consume approximately $16 \mu \mathrm{L}$ of nectar (see Eq. 4) if all sucrose daily needs is to be covered from $N$. glauca nectar. Considering the significant fluctuation of anabasine concentration in N. glauca nectar ranging from $0.39 \mu \mathrm{g} / \mathrm{mL}$ [22], to $5 \mu \mathrm{g} / \mathrm{mL}$ [16] a single honeybee may be exposed daily from 6 to $80 \mathrm{ng}$ of anabasine (see Eq. 5).

$$
D N C_{e}=S D N \times \frac{N P_{\text {mean }}}{\text { Conc }_{\text {SUCROSE-nectar }}}
$$

$$
\operatorname{Exp}=D N C \times \operatorname{Conc}_{\text {Anab }}
$$

$\mathrm{DNC}_{\mathrm{e}}$, daily nectar consumption estimate $(\mu \mathrm{L}) ; \mathrm{SDN}$, sucrose daily need $(\mu \mathrm{g})$; NPmean, average nectar pro-

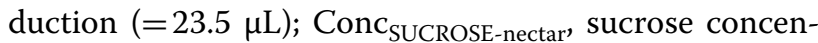
tration in $N$. glauca nectar; Exp, bees daily anabasine

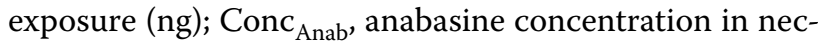
$\operatorname{tar}(\mu \mathrm{g} / \mathrm{mL})$.

\section{Discussion}

The active ingredient of the feeding solution was the flower extract of $N$. glauca. The reason behind this choice over the nectar extract is related to the foraging habits of the honeybees on N. glauca flowers. In specific as clearly stated by Ollerton et al. [17] nectar robbers pierce the corolla, or make use of previous holes, and honeybees are totally capable to cut a hole in the corolla with their mandibles. The $10 \mu \mathrm{g} / \mathrm{mL}$ concentration was used as a focal point of our study. Such concentration was also assessed in feeding responses as presented by Singaravelan et al. (in artificial nectar) [30], and is approximately double the mean concentration in nectar reported by Tadmor-Melamed et al. [16].

It must be noted that honeybees' foraging in N. glauca requires the consumption of herbal tissue to reach the flower's nectar, as evidenced by our group and depicted by Ollerton et al. [17]. It is also noteworthy that damaging of petals-flowers by honeybees was evidenced (see also a respective photo taken during bees visiting $N$. glauca in Greece, Fig. 1), a fact known to elicit the alkaloidal response in Nicotiana spp. manifesting increase in concentrations in flowers and nectar. In addition, and as mentioned by Adler and colleagues, leaf alkaloid levels in Nicotiana tabacum are higher than the nectar alkaloid levels (mg/g compared to $\mu \mathrm{g} / \mathrm{g}$, respectively) [41], which can be hypothesized for $N$. glauca accordingly. Research findings concerning alkaloid levels in other species, such as lupin (Lupinus L. spp.), demonstrated higher levels of alkaloids in inflorescences, with respect to leaves, and stems [42]. Similarly, Gosselin et al. reported that 


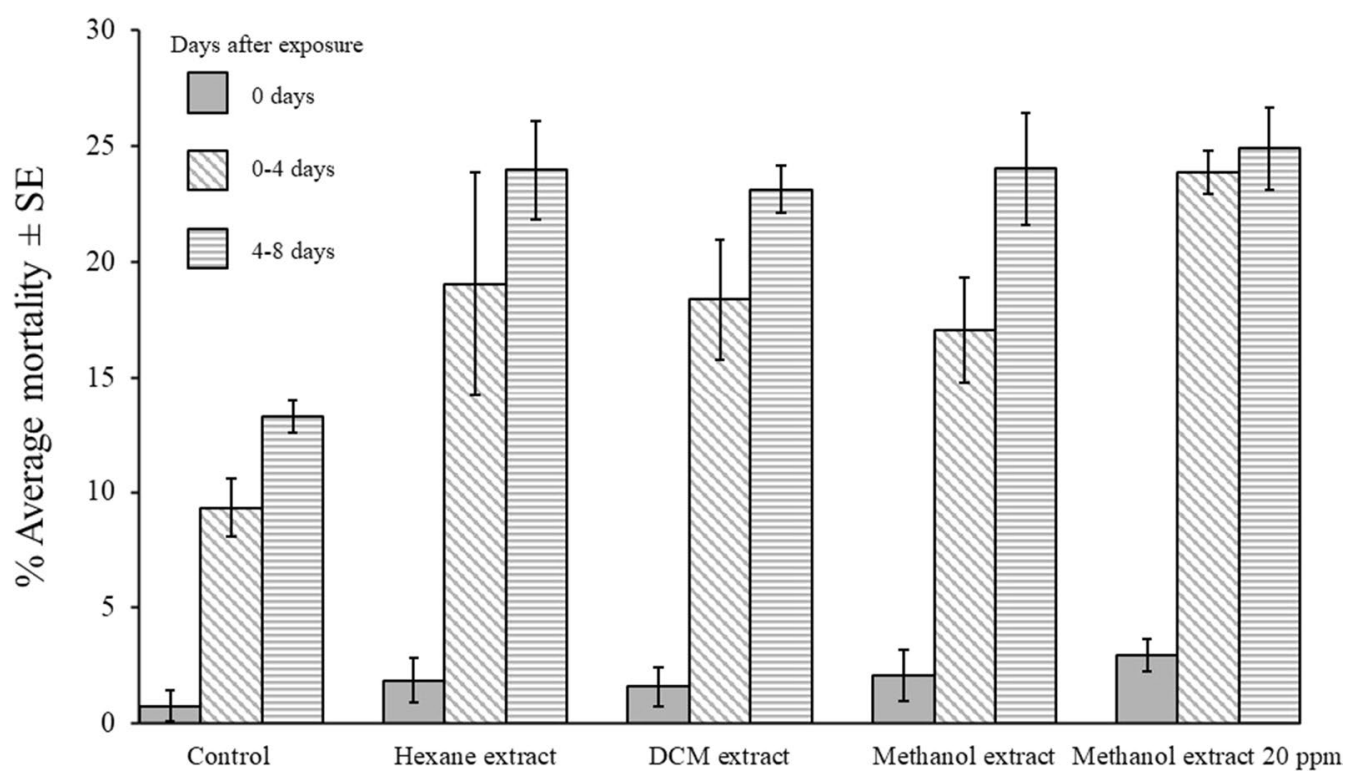

Fig. 2 Average mortality of Apis mellifera young workers at 0,4, and 8 days after feeding for $24 \mathrm{~h}$ on N. glauca extracts

Table 3 Honeybees' daily estimated exposure to alkaloids of Nicotiana glauca feeding solutions (in ng per bee) and mean

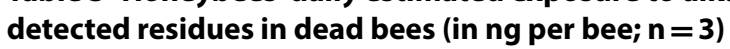

\begin{tabular}{|c|c|c|c|c|c|c|c|c|}
\hline \multirow{2}{*}{$\begin{array}{l}\text { Feeding } \\
\text { solution }\end{array}$} & \multicolumn{2}{|l|}{ Anabasine } & \multicolumn{2}{|l|}{ Anatabine } & \multicolumn{2}{|c|}{ Nornicotine } & \multicolumn{2}{|l|}{ Scopoletin } \\
\hline & Exposure & Residue & Exposure & Residue & Exposure & Residue & Exposure & Residue \\
\hline Hexane & 1040 & $4.3 \pm 0.19$ & nd & nd & nd & nd & nd & nd \\
\hline $\begin{array}{l}\text { Dichlo- } \\
\text { romethane }\end{array}$ & 1040 & $4.7 \pm 0.3$ & 12 & nd & nd & nd & nd & nd \\
\hline Methanol & 1040 & $5.1 \pm 0.27$ & 10 & nd & 3 & nd & 11 & $<\mathrm{LOQ}$ \\
\hline $\begin{array}{l}\text { Methanol } \\
\text { extract } \\
20 \mu \mathrm{g} / \mathrm{mL}\end{array}$ & 2080 & $9.2 \pm 0.52$ & 20 & nd & 6 & nd & 22 & $<\mathrm{LOQ}$ \\
\hline
\end{tabular}

nd non-detected, LOQ $4 \mathrm{ng}$ per bee or $40 \mathrm{ng} / \mathrm{g}$ bee bw

alkaloids of toxic plant Aconitum septentrionale (Ranunculaceae) display lower concentrations in nectar compared to leaves and flowers. Hence, it cannot be excluded that bees can potentially be exposed to higher alkaloids' concentrations than the ones present in non-damaged flowers or even nectar, which to a degree, can justify the $10 \mu \mathrm{g} / \mathrm{mL}$ concentration used in the assay. Such approach can also compromise the absence of nectar in testing and bridge the difference in estimated exposure and exposure dose(s) administered.

Interestingly, Pashalidou and colleagues reported that bumblebees in the scarcity of pollen, damage plant leaves stimulating flower production [43]. In this regard, it can be assumed that if bees experience respective scarcity in N. glauca, can further damage its leaves and flowers, which might lead to augmented alkaloids concentration. Nevertheless, it was not the case in this work due to the time of the sampling ( N. glauca exhibits substantial blooming within August).

The increased mortality provoked by the administration of the methanol extract at $20 \mu \mathrm{g} / \mathrm{mL}$, indicates that this observation might be connected to the presence of anabasine, which is a known insect control agent [44]. The potential association of anabasine with bees' mortality should be treated with caution, considering that the administered plant extracts may contain other plant toxins, not included in the analytical method. Nevertheless, studies on $N$. glauca content have demonstrated several constituents such as sesquiterpenes, diterpenoids, and phenols in addition to alkaloids $[45,46]$. In this context, such compounds although prevalent, are not expected to provoke substantial effects on bees, not omitting of course the combined effects that are to a large extent underexplored. For example, recent work on the 
beneficial role of such components showed that the terpenes of various parts of thyme inhibited the growth of bee disease associated microbes [47].

Singaravelan et al. [30] investigating the effects of free-flying bees' exposure to secondary compounds that mimic floral nectars reported that anabasine was shown to deter honeybees, with the more profound effect being observed at the $25 \mu \mathrm{g} / \mathrm{mL}$ dose. In an ensuing study though delineating the nicotine impacts on honeybees, it was stressed that symptoms and mortality need to be examined in the context of the overall hygiene and bee health status [48]. Even though previous research results provide advocacy for present findings, are not directly comparable regarding the parameters examined herein, dictating that the role of anabasine in bees mortality needs to be investigated further through experimentation detailing the dose-response phenomena in a prolonged time frame. Nevertheless, present findings report for the first time the alkaloid content of N. glauca flowers, documenting them as a prominent source of invasive molecules in organisms foraging its flowers.

To estimate the bee's daily alkaloid consumption was considered the maximum daily nectar consumption of $128 \mathrm{mg} / \mathrm{bee}$ for forager honeybees [49] and the density of the $50 \% \mathrm{w} / \mathrm{v}$ sucrose aqueous solution used $(1.23 \mathrm{~g} / \mathrm{mL}$, $20{ }^{\circ} \mathrm{C}$ ). Based on these assumptions the dose of anabasine in which a single honeybee was exposed within the $24 \mathrm{~h}$-feeding period is determined at $1.04 \mu \mathrm{g} /$ bee in feeding solution concentration of $10 \mu \mathrm{g} / \mathrm{mL}$, and at $2.08 \mu \mathrm{g} /$ bee in feeding solution concentration of $20 \mu \mathrm{g} / \mathrm{mL}$. Minor discrepancies in the detected residues, among the three feeding solutions, might indicate differential behaviour of bees as regard the plant extract uptake during experimentation and/or differential metabolism within individual bees. The differences in mean measured concentrations in bees compared to the external doses are expected, considering that the internal dose is dependent on several factors. Among them, the most pivotal is the toxicant's half-life $\left(t_{1 / 2}\right)$, also mentioned in the European Food Safety Authority (EFSA) guidance document on risk assessment on bees [49]. More specifically, once an animal stops to be exposed to the toxicant, the anticipated time for its virtual elimination from the animal's body is five-times its $t_{1 / 2}$ [49]. Anabasine shares similar $t_{1 / 2}$ with nicotine (2-3 $\mathrm{h}$ in plasma) [50], which along with the sampling time and the low bioaccumulation potential of the polar anabasine (and related alkaloids) can justify the low concentrations detected. The attribution of the residual quantities in individual bees indicates the possibility of the potential transfer of these residues inside the beehive (see paragraph below).

Considering the sample preparation for alkaloids extraction from bees, it was based on two approaches: (a) a methanolic and/or ethyl acetate direct extraction of alkaloids, using only a reconstitution (for ethyl acetate) and a drying step prior to chemical analysis and, (b) a modified QuEChERS protocol. The consideration of the QuEChERS methodology was attempted considering its extensive use in pesticides and organic contaminants sample preparation (and consequent analysis), and the possible introduction of alkaloids in such multiresidue schemes (nicotine possesses insecticidal properties). Specialized methods for alkaloids extraction exist, taking advantage of the acidobasic features and differences of various alkaloids solubility. Nevertheless, they were not implemented due to the more tedious sample preparation. Other laboratory trials (data not shown) on the optimization of QuEChERS protocol were attempted, especially on the $\mathrm{pH}$ adjustment (basic using $\mathrm{NH}_{3}$ or $\mathrm{NaOH}, \mathrm{pH} \sim 9$ to 10 on the first step, and addition of formic acid solution to reach a $\mathrm{pH} \sim 5$ at the last step). Since the results were comparable to the sodium acetate standard procedure, we selected the latter as the final choice. In the end, both approaches (direct organic solvent and QuEChERS extraction) were efficient on recovering the targeted compounds as demonstrated by analytical method performance, with QuEChERS protocol, yielding cleaner extracts, therefore it was selected and fully validated. Alkaloids have been adequately extracted using QuEChERS from tea [51], tobacco [52], feed [53] and honey [54]. Therefore, this work contributes to the frontier of alkaloids extraction from another matrix (honeybees).

With regard to the hydrophilic stationary phase, it encourages partition of the analytes (in this case, the alkaloids and scopoletin) in the stationary water phase that is formed within the column. In addition, the preliminary comparison of RP with HILIC mode showed that the latter exhibited higher sensitivity for all analytes, possibly due to easier desolvation of the mobile phase (contained less water than the respective of RP) during the electrospray ionization.

In this context, HILIC was implemented. The latter additionally exhibited superior performance compared to RP, C18 chromatography (for C18 chromatography see chromatogram in Additional file 1: Figure S6), improving the separation between the isomers especially for $( \pm)$-nicotine and $(R, S)$-anatabine, furnishing better chromatographic peak shapes for the majority of analytes, which is depicted in Fig. 3. With regard to the mobile phase selection, the trademark of low water content under HILIC conditions was verified in this study as well. Compared to previous work [31], the elution order of common analytes was verified, however in the present work the inclusion of more analytes, that in the HILIC mode were expected to elute early (such 


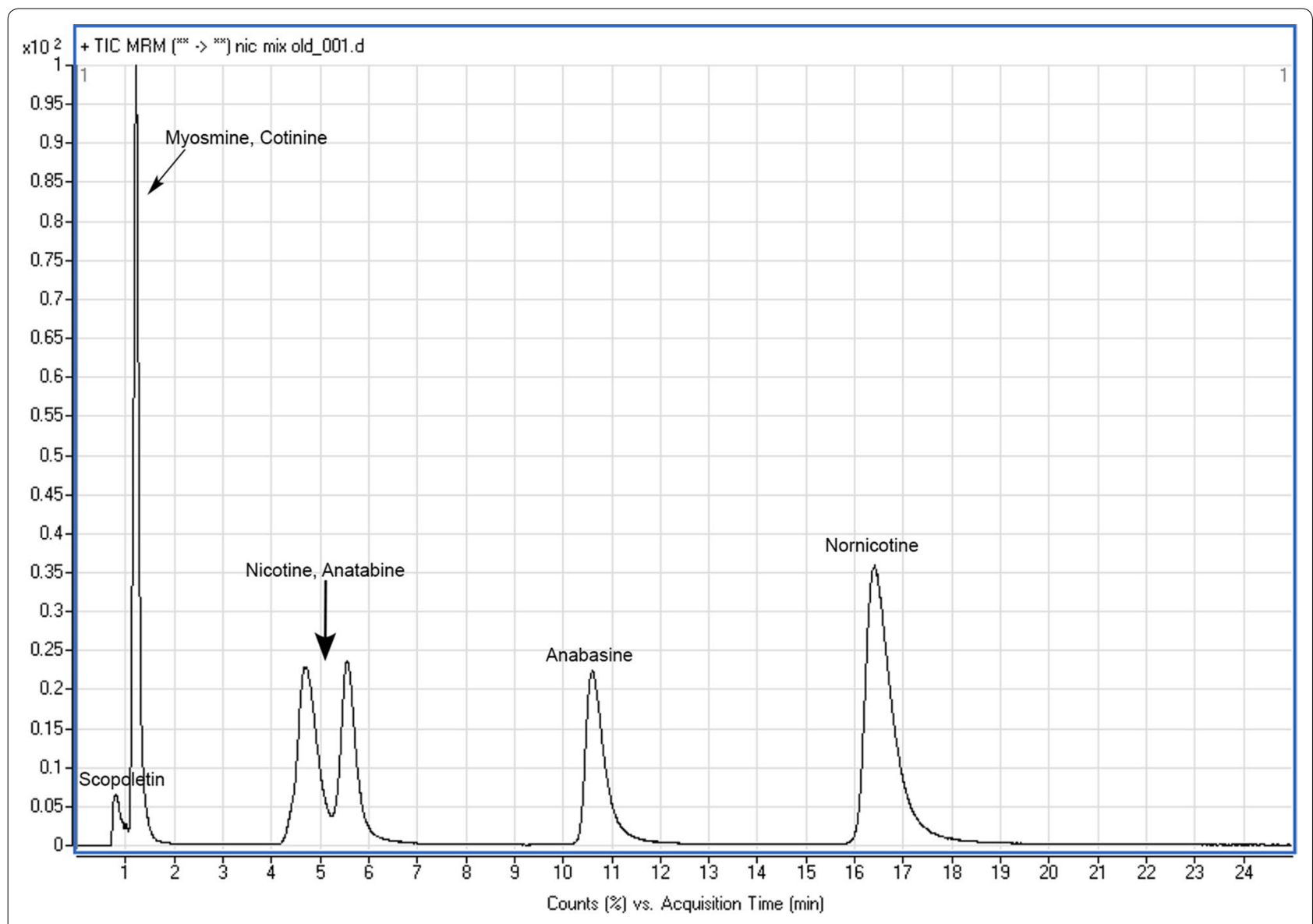

Fig. 3 HILIC-ESI-MS/MS chromatogram of a 0.5 ppm standard solution of alkaloids mix

as scopoletin and myosmine), led to a decrease of the flow rate, selection of a column with larger film thickness; hence, enhancing the separation, though increasing the retention. Apart from the work of Taujenis and coworkers, a 2006 report showed also how the HILIC conditions employing low water amounts, favor the resolution and chromatographic performance of other alkaloids based on xanthine [55]. In previous studies, HILIC mode conditions were reported successful in separating low resolution isomers of dansyl amino acids and nicotine enantiomers analogs [56, 57]. A recent LC coupled to high resolution mass spectrometry (HRMS) research work also demonstrated the importance and optimum performance of HILIC in the separation of nortropane alkaloids (calystegines) in tomato-based products [58]. A clear advantage of this analytical work (and related works on alkaloids separation using HILIC) seems to be the distinct separation of anabasine and nicotine, whose structural-chromatographic differentiation is still a challenging topic [59].

To conclude, acknowledging the expansion of tobacco tree in the Northern Mediterranean coast, bees were placed in the center of this study, since along with other wild insects have been recorded feeding on its plentiful nectar. Therefore, the fundamental question was raised: do tobacco alkaloids, which have been defined as potent insecticides, penetrate in the foraging organisms? To answer this question, a novel method was developed to be able to quantify the tobacco tree alkaloids in the flower extracts and bees, and then a feeding bioassay in bees was performed. The proposed analytical methodology succeeded to detail the alkaloid content of the extracts and to provide qualitative and quantitative definition of the alkaloids residues in bees. The feeding bioassay provided indications of low to medium toxicity of the extracts but more importantly defined the alkaloid content of the dead bees, though in nature consumption by other organisms, is sparingly documented, focused to bee-eater birds (Coraciiformes: Meropidae) [60]. The impacts of Nicotiana alkaloids in honeybees were explicitly summarized by Stevenson et al. (2017) [61], identifying foraging repellent and attractive impacts depending on concentration a null impact on the survival of adult bees, which agrees with present findings, but also a reduced larvae 
survival rate both in vivo and in vitro. On the other hand, it a chemoprotective impact on the reduction in Crithidia bombi infection was also reported [62]. These facts in cross consideration with present findings advocate on the role and significance of the reported phenomenon on honeybee's population dynamics. After all, Neov et al. (2019) [63] argued in favor of the role of feeding disorder in the beehives health status, also recognizing the significant impacts of neonicotinoids, agrochemicals defined as pyridine alkaloids. The role and significance of invasive alien species as honeybees feed sources has been stressed by Donkersley et al. [64] that identified a primary pollen source in the form of the invasive Himalayan balsam, providing a previous report that advocates the primary role of Nicotiana glauca as a honeybee feed source in arid Mediterranean habitats, especially through seasons with scarce flowering. On the contrary, the most important aspect not to be neglected is the transfer of such compounds in the beehive by forager honeybees and potentially to apiculture products, exemplified by honey. Such transfer though remains to be proven. Alkaloids in honey, such as pyrrolizidine based molecules (e.g., echimidine), are intensively studied in terms of residual prevalence $[65,66]$ and some of the members display carcinogenic, hepatotoxic and other toxic pharmacological activities [67]. Despite their toxicity, the European Commission has not yet established their MRLs.

Similarly, and with regard to pyridine alkaloids, such as nicotine and anabasine, none specific MRL is defined in honey. Therefore the general default MRL of $0.01 \mathrm{mg} /$ $\mathrm{kg}$ can be regarded. Consequently, from the results of the presented study and the detection of anabasine in bees it can be assumed that the beehive might get contaminated from these alkaloids, and residues can be transferred to the honey produce and the food chain. Nevertheless, EFSA states that MRL of nicotine in different commodities ranging from $0.3-4 \mathrm{mg} / \mathrm{kg}$, is not risk for consumers [68].

\section{Supplementary information}

Supplementary information accompanies this paper at https://doi. org/10.1186/s12898-020-00325-3.

\footnotetext{
Additional file 1. Figure S1. TIC LC-ESI-MS/MS chromatogram of blank bees' QuEChERS extract. Figure S2. Poor resolution of ( \pm )-nicotine and $(R, S)$-anatabine under reversed phase chromatographic conditions ${ }^{a}$. Figure S3. A-G Retention times and MRM ion transitions ( $\mathrm{m} / \mathrm{z})$ used in analysis by HILIC chromatography. Figure S4. Overlayed TIC chromatogram, and MRM chromatogram for anabasine in a Nicotiana glauca $\mathrm{MeOH}$ extract (100 ppm) $)^{a}$. Figure S5. TIC chromatogram (and MRM chromatogram of quantitation transition of anabasine) in bees. Figure S6. TIC LCESI-MS/MS chromatogram of a standard solution at 2 ppm of analytical standards mix using classical C18 column, and indicative MRM chromatograms (scopoletin, anatabine, myosmine and cotinine). Table S1. Bioactive components concentrations $(\mu \mathrm{g} / \mathrm{mL})$ in administered Nicotiana glauca extracts. Table S2. Analytical Method Validation Characteristics for
}

the Nicotiana glauca hexane extract. Table S3. Analytical Method Validation Characteristics for the Nicotiana glauca dichloromethane extract. Table S4. Analytical Method Validation Characteristics in honeybees using the QuEChERS protocol.

\begin{abstract}
Abbreviations
Conc $_{\text {Anab: }}$ : Anabasine concentration in nectar; NPmean: Average nectar production; Exp: Bees daily anabasine exposure; DNC: Daily nectar consumption estimate; LOD: Detection limit; EFSA: European Food Safety Authority; HILIC: Hydrophilic interaction chromatography; IAS: Invasive Alien Species; $\mathrm{MgSO}_{4}$ : Magnesium sulphate; ME: Matrix effect; $\mathrm{LD}_{50}$ : Median lethal dose; LC-ESI-MS/ MS: Liquid chromatography electrospray tandem mass spectrometry; MRLs: Maximum residue limits; MRM: Multiple Reaction Monitoring; C18: Octyldecylsilane; OECD: Organization for Economic Co-operation and Development; PSA: Primary secondary amine; LOQ: Quantitation limit; QuEChERS: "Quick, easy, cheap, effective, rugged, and safe"; RSD: Relative standard deviation; RP: Reversed phase; Conc SUCROSE-nectar: Sucrose concentration in N. glauca nectar; SDN: Sucrose daily need; TIC: Total ion chromatogram.
\end{abstract}

\section{Acknowledgements}

Not applicable.

\section{Authors' contributions}

$\mathrm{KMK}$ and $\mathrm{EE}$, conceived and designed the research. KMK, EE, DP, SA, and OV, conducted lab and assays work. In particular, KMK performed the chemical analyses, DP organized and conducted the bees'feeding assay, and the respective statistical analyses. EE and OV performed the phytochemical part. KMK and EE, wrote the manuscript, while PM, DP, SAH, and KM edited and contributed to the manuscript. All authors have read and approved the final manuscript.

\section{Funding}

Not applicable.

\section{Availability of data and materials}

All necessary data and materials are presented in the manuscript and in the supplementary material.

\section{Ethics approval and consent to participate}

Benaki Phytopathological Institute's ethics committee (in which bees assays were conducted) reviewed and approved the study.

\section{Consent for publication}

Not applicable.

\section{Competing interests}

The authors declare that they have no competing interests.

\section{Author details}

${ }^{1}$ Laboratory of Pesticides'Toxicology, Department of Pesticides Control and Phytopharmacy, Benaki Phytopathological Institute, 8 St. Delta str., 14561 Kifissia, Attica, Greece. ${ }^{2}$ Laboratory of Nutritional Physiology and Feeding, Agricultural University of Athens, lera Odos 75, 11855 Athens, Greece.

${ }^{3}$ Laboratory of Agricultural Entomology, Department of Entomology and Agricultural Zoology, Benaki Phytopathological Institute, 8 St. Delta str., 14561 Kifissia, Attica, Greece. ${ }^{4}$ Biological Control Laboratory, Department of Entomology and Agricultural Zoology, Benaki Phytopathological Institute, 8 St. Delta str., 14561 Kifissia, Attica, Greece.

Received: 30 March 2020 Accepted: 26 October 2020

Published online: 06 November 2020

\section{References}

1. Pimentel D, Zuniga R, Morrison D. Update on the environmental and economic costs associated with alien-invasive species in the United States. Ecol Econ. 2005;52(3):273-88. 
2. REGULATION-(EU)-No-1 143/2014. Regulation (EU) No 1143/2014 of the European Parliament and of the Council of 22 October 2014 on the prevention and management of the introduction and spread of invasive alien species. Off J Eur Union 2014.

3. Kates RW. Invasive alien species: musings on a spring morning. Environment. 2004;46(6):Cover2.

4. Nikolic T, Mitic B, Milasinovic B, Jelaska SD. Invasive alien plants in Croatia as a threat to biodiversity of South-Eastern Europe: distributional patterns and range size. Cr Biol. 2013;336(2):109-21.

5. Celesti-Grapow L, Bassi L, Brundu G, Camarda I, Carli E, D'Auria G, De Guacchio E, Domina G, Ferretti G, Foggi B, et al. Plant invasions on small Mediterranean islands: an overview. Plant Biosyst. 2016;150(5):1119-33.

6. Gonzalez-Varo JP, Biesmeijer JC, Bommarco R, Potts SG, Schweiger O, Smith HG, Steffan-Dewenter I, Szentgyorgyi H, Woyciechowski M, Vila M. Combined effects of global change pressures on animal-mediated pollination. Trends Ecol Evol. 2013;28(9):524-30.

7. Tiedeken EJ, Egan PA, Stevenson PC, Wright GA, Brown MJF, Power EF, Farrell I, Matthews SM, Stout JC. Nectar chemistry modulates the impact of an invasive plant on native pollinators. Funct Ecol. 2016;30(6):885-93.

8. Graves SD, Shapiro AM. Exotics as host plants of the California butterfly fauna. Biol Conserv. 2003;110(3):413-33.

9. Stout JC, Morales CL. Ecological impacts of invasive alien species on bees. Apidologie. 2009;40(3):388-409.

10. Drossart M, Michez D, Vanderplanck M. Invasive plants as potential food resource for native pollinators: a case study with two invasive species and a generalist bumble bee. Sci Rep. 2017;7(1):16242.

11. Adler LS. The ecological significance of toxic nectar. Oikos. 2000;91(3):409-20.

12. REGULATION-(EC)-No-396/2005. Regulation (EC) No 396/2005 of the European Parliament and of the Council, on maximum residue levels of pesticides in or on food and feed of plant and animal origin and amending Council Directive 91/414/EEC. Off J Eur Union. 2005; L70.

13. Adler LS, Irwin RE. Nectar alkaloids decrease pollination and female reproduction in a native plant. Oecologia. 2012;168(4):1033-41.

14. Bennett RN, Wallsgrove RM. Secondary metabolites in plant defensemechanisms. New Phytol. 1994;127(4):617-33.

15. Mollo E, Cimino G, Ghiselin MT. Alien biomolecules: a new challenge for natural product chemists. Biol Invasions. 2015;17(3):941-50.

16. Tadmor-Melamed H, Markman S, Arieli A, Distl M, Wink M, Izhaki I. Limited ability of Palestine Sunbirds Nectarinia osea to cope with pyridine alkaloids in nectar of Tree Tobacco Nicotiana glauca. Funct Ecol. 2004:18(6):844-50.

17. Ollerton J, Watts S, Connerty S, Lock J, Parker L, Wilson I, Scueller SK, Nattero J, Cocucci AA, Izhaki I, et al. Pollination ecology of the invasive tree tobacco Nicotiana glauca: comparisons across native and non-native ranges. J Poll Ecol. 2012;9(12):85-95.

18. Blank F. Alkaloid formation in roots [Alkaloidbildung in der Pflanzenwurzel]. Experientia. 1945;1:111-5.

19. Pyriki C, Oehler K. Occurrence of anabasine in Nicotiana glauca. Pharmazie. 1954;9(8):685-8.

20. Baldwin IT, Ohnmeiss TE. Alkaloidal responses to damage inNicotiana native to North America. J Chem Ecol. 1993;19(6):1143-53.

21. Sinclair SJ, Johnson R, Hamill JD. Analysis of wound-induced gene expression in Nicotiana species with contrasting alkaloid profiles. Funct Plant Biol. 2004;31(7):721-9.

22. Kaczorowski RL, Koplovich A, Sporer F, Wink M, Markman S. Immediate effects of nectar robbing by Palestine sunbirds (Nectarinia osea) on nectar alkaloid concentrations in tree tobacco (Nicotiana glauca). J Chem Ecol. 2014:40(4):325-30.

23. Aizenberg-Gershtein Y, Izhaki I, Santhanam R, Kumar P, Baldwin IT, Halpern M. Pyridine-type alkaloid composition affects bacterial community composition of floral nectar. Sci Rep. 2015:5:11536.

24. Kaczorowski RL, Markman S. Nectar alkaloids of tree tobacco can reduce Palestine sunbird foraging performance in a colour discrimination task. Anim Behav. 2016;1 19:59-68.

25. https://sitem.herts.ac.uk/aeru/bpdb/Reports/485.htm

26. https://sitem.herts.ac.uk/aeru/bpdb/Reports/1690.htm

27. https://foodb.ca/compounds/FDB023374

28. https://sitem.herts.ac.uk/aeru/ppdb/en/Reports/2560.htm

29. https://foodb.ca/compounds/FDB012705
30. Singaravelan N, Nee'man G, Inbar M, Izhaki I. Feeding responses of freeflying honeybees to secondary compounds mimicking floral nectars. J Chem Ecol. 2005;31(12):2791-804.

31. Taujenis $L$, Olsauskaite V, Padarauskas A. Determination of nicotine and three minor alkaloids in tobacco by hydrophilic interaction chromatography-tandem mass spectrometry. Acta Chromatogr. 2015;27(2):373-85.

32. Kasiotis KM, Anagnostopoulos C, Anastasiadou P, Machera K. Pesticide residues in honeybees, honey and bee pollen by LC-MS/MS screening: reported death incidents in honeybees. Sci Total Environ. 2014;485-486:633-42.

33. ICH. Validation of analytical procedures: text and methodology Q2(R1) https://www.ichorg/fileadmin/Public_Web_Site/ICH_Products/Guide lines/Quality/Q2_R1/Step4/Q2_R1_Guideline.pdf. 2005.

34. Betz JM, Brown PN, Roman MC. Accuracy, precision, and reliability of chemical measurements in natural products research. Fitoterapia. 2011:82(1):44-52.

35. Buszewski B, Noga S. Hydrophilic interaction liquid chromatography (HILIC)-a powerful separation technique. Anal Bioanal Chem 2012;402(1):231-47.

36. Leete E, Chedekel MR. Metabolism of nicotine in Nicotiana-Glauca. Phytochemistry. 1974;13(9):1853-9.

37. Tabana YM, Hassan LEA, Ahamed MBK, Dahham SS, labal MA, Saeed MAA, Khan MSS, Sandai D, Majid ASA, Oon CE, et al. Scopoletin, an active principle of tree tobacco (Nicotiana glauca) inhibits human tumor vascularization in xenograft models and modulates ERK1, VEGF-A, and FGF-2 in computer model. Microvasc Res. 2016;107:17-33.

38. OECD-Honeybee-Acute-Oral-Toxicity. OECD guidelines for the testing of chemicals honeybees, Acute Oral Toxicity Test. 1998.

39. Barker RJ, Lehner Y. Acceptance and sustenance value of naturally occurring sugars fed to newly emerged adult workers of honey bees (ApisMellifera-L). J Exp Zool. 1974:187(2):277-85.

40. Brodschneider R, Crailsheim K. Nutrition and health in honey bees. Apidologie. 2010;41(3):278-94.

41. Adler LS, Wink M, Distl M, Lentz AJ. Leaf herbivory and nutrients increase nectar alkaloids. Ecol Lett. 2006;9(8):960-7.

42. Maknickiene Z, Asakaviciute R. Alkaloid content variations in lupin (Lupinus L.) genotypes and vegetation periods. Biologija. 2008;54(2):112-5.

43. Pashalidou FG, Lambert H, Peybernes T, Mescher MC, De Moraes CM. Bumble bees damage plant leaves and accelerate flower production when pollen is scarce. Science. 2020;368(6493):881-4.

44. Garman P. Notes of the comparative toxicity of anabasine sulfate and nicotine sulfate for aphis and leafhoppers. Conn State Agr Expt Sta Bull. 1933;349:433-4.

45. Trifa W, Akkal S, Lefahal M, Benmekhebi L, Khennouf S. Preliminary screening of Nicotiana glauca extracts for determination of antioxidant activity by different methods. Curr Iss Pharm Med S. 2020;33(1):32-7.

46. Aldesuquy HS, Mashaly IA, El-Aal MA, Mahdee BA. Phytochemical constituents, antibacterial and antioxidant activities of some medicinal plants. Curr Trends Biomedical Eng Biosci. 2018;16(2):47-55.

47. Wiese N, Fischer J, Heidler J, Lewkowski O, Degenhardt J, Erler S. The terpenes of leaves, pollen, and nectar of thyme (Thymus vulgaris) inhibit growth of bee disease-associated microbes. Sci Rep. 2018;8(1):14634.

48. Singaravelan N, Inbar M, Ne'eman G, Distl M, Wink M, Izhaki I. The effects of nectar-nicotine on colony fitness of caged honeybees. J Chem Ecol. 2006:32(1):49-59.

49. EFSA-Guidance. EFSA Guidance Document on the risk assessment of plant protection products on bees (Apis mellifera, Bombus spp. and solitary bees). EFSA J. 2013;11(7):3295.

50. Cruickshank-Quinn Cl, Mahaffey S, Justice MJ, Hughes G, Armstrong M, Bowler RP, Reisdorph R, Petrache I, Reisdorph N. Transient and persistent metabolomic changes in plasma following chronic cigarette smoke exposure in a mouse model. PLOS ONE. 2014:9(7):e101855.

51. Thrane C, Isemer C, Engelhardt UH. Determination of nicotine in tea (Camellia sinensis) by LC-ESI-MS/MS using a modified QuEChERS method. Eur Food Res Technol. 2015;241(2):227-32.

52. Li XT, Liu F, Wang HF, He F, Yang R, Zhao MQ. Gas chromatography-mass spectrometry method for simultaneous detection of nine alkaloids in tobacco and tobacco products by QuEChERS sample preparation. Anal Sci. 2019;35(8):849-54.

53. Leon N, Pastor A, Yusa V. Target analysis and retrospective screening of veterinary drugs, ergot alkaloids, plant toxins and other undesirable 
substances in feed using liquid chromatography-high resolution mass spectrometry. Talanta. 2016;149:43-52.

54. Martinello M, Borin A, Stella R, Bovo D, Biancotto G, Gallina A, Mutinell F. Development and validation of a QuEChERS method coupled to liquid chromatography and high resolution mass spectrometry to determine pyrrolizidine and tropane alkaloids in honey. Food Chem. 2017;234:295-302.

55. Puy G, Demesmay C, Rocca JL, lapichella J, Galarneau A, Brunel D. Electrochromatographic behavior of silica monolithic capillaries of different skeleton sizes synthesized with a simplified and shortened sol-gel procedure. Electrophoresis. 2006;27(20):3971-80.

56. Han SM, Armstrong DW. Use of microcolumn liquid chromatography with a chiral stationary phase for the separation of low-resolution enantiomers. J Chromatogr. 1987;389(1):256-60.

57 Seeman JI, Secor HV, Armstrong DW, Timmons KD, Ward TJ. Enantiomeric resolution and chiral recognition of racemic nicotine and nicotine analogues by beta-cyclodextrin complexation. Structure-enantiomeric resolution relationships in host-quest interactions. Anal Chem. 1988;60(19):2120-7.

58. Romera-Torres A, Romero-Gonzalez R, Martinez Vidal JL, Garrido Frenich A. Analysis of calystegines in tomato-based products by liquid chromatography-Orbitrap mass spectrometry. J Chromatogr A. 2018;1576:51-7.

59. Tyrkko E, Pelander A, Ojanpera I. Prediction of liquid chromatographic retention for differentiation of structural isomers. Anal Chim Acta. 2012;720:142-8.

60. Glaiim MK. Occurrence and status of bee-eaters, Merops spp. (Coraciiformes: Meropidae), and their attacks on honey bee colonies in Kerbala Province, Iraq. J Apicult Res. 2014;53(4):478-88.

61. Stevenson PC, Nicolson SW, Wright GA. Plant secondary metabolites in nectar: impacts on pollinators and ecological functions. Funct Ecol. 2017;31(1):65-75
62. Richardson LL, Adler LS, Leonard AS, Andicoechea J, Regan KH, Anthony WE, Manson JS, Irwin RE. Secondary metabolites in floral nectar reduce parasite infections in bumblebees. Proc Biol Sci. 1803;2015(282):20142471.

63. Neov B, Georgieva A, Shumkova R, Radoslavov G, Hristov P. Biotic and abiotic factors associated with colonies mortalities of managed honey bee (Apis mellifera). Diversity-Basel. 2019. https://doi.org/10.3390/d1112 0237.

64. Donkersley P, Rhodes G, Pickup RW, Jones KC, Power EF, Wright GA, Wilson K. Nutritional composition of honey bee food stores vary with floral composition. Oecologia. 2017;185(4):749-61.

65. Sixto A, Niell S, Heinzen H. Straightforward determination of pyrrolizidine alkaloids in honey through simplified methanol extraction (QUPPE) and LC-MS/MS modes. Acs Omega. 2019;4(27):22632-7.

66. Hungerford NL, Carter SJ, Anuj SR, Tan BLL, Hnatko D, Martin CL, Sharma E, Yin M, Nguyen TTP, Melksham KJ, et al. Analysis of pyrrolizidine alkaloids in Queensland honey: Using Low Temperature chromatography to resolve stereoisomers and identify botanical sources by UHPLC-MS/MS Toxins. 2019. https://doi.org/10.3390/toxins 11120726.

67. Wiedenfeld $\mathrm{H}$. Plants containing pyrrolizidine alkaloids: toxicity and problems. Food Addit Contam Part A Chem Anal Control Expo Risk Assess. 2011;28(3):282-92.

68. EFSA-Nicotine. Setting of temporary MRLs for nicotine in tea, herbal infusions, spices, rose hips and fresh herbs. EFSA J. 2011;9(3):2098. https://doi. org/10.2903/j.efsa.2011.2098.

\section{Publisher's Note}

Springer Nature remains neutral with regard to jurisdictional claims in published maps and institutional affiliations.
Ready to submit your research? Choose BMC and benefit from:

- fast, convenient online submission

- thorough peer review by experienced researchers in your field

- rapid publication on acceptance

- support for research data, including large and complex data types

- gold Open Access which fosters wider collaboration and increased citations

- maximum visibility for your research: over $100 \mathrm{M}$ website views per year

At BMC, research is always in progress.

Learn more biomedcentral.com/submissions 